\title{
FGFR2, FGF8, FGF10 and BMP7 as candidate genes for hypospadias
}

\author{
Ana Beleza-Meireles ${ }^{*, 1,4}$, Fredrik Lundberg ${ }^{1,4}$, Kristina Lagerstedt ${ }^{1}$, Xiaolei Zhou ${ }^{1}$, \\ Davood Omrani $^{1,2}$, Louise Frisén ${ }^{1}$ and Agneta Nordenskjöld ${ }^{1,3}$
}

\begin{abstract}
${ }^{1}$ Department of Molecular Medicine and Surgery, Karolinska University Hospital, Karolinska Institutet, Stockholm, Sweden; ${ }^{2}$ Department of Genetics, Faculty of Medicine, Uromieh Medical Sciences University, Uromieh, Iran; ${ }^{3}$ Department of Women and Child Health, Astrid Lindgren Children Hospital, Karolinska University Hospital, Stockholm, Sweden
\end{abstract}

Hypospadias is a common malformation, which results from failure of urethral tube closure, and whose molecular mechanisms are still largely unknown. The normal genital development is orchestrated by the urethral plate epithelium (UPE), at the genital tubercle (GT), which has polarizing activity, controlling a network of epithelial-mesenchymal interactions, which, when disturbed, may lead to hypospadias. Homeobox proteins (HOXs), fibroblast growth factors (FGFs) and bone morphogenic proteins (BMPs) are essential in this process. Hypospadias in the Hoxa13 -/- mice occurs as a result of the combined loss of Fgf8 and Bmp7 expression in the UPE. In both Fgf10 and Fgfr2 deficient mutant hypospadic male mice, cell proliferation is arrested prematurely and the maturation of the urethral epithelium is disrupted. Fgf8, Fgf10, and their receptor Fgfr2 are downstream targets of androgens (AR) during external genital development, an important fact given the pivotal role of AR in male sex differentiation. Therefore, we examined FGFR2, FGF10, FGF8, and BMP7 as candidate genes for hypospadias. DNA from 60 boys with familial, isolated, hypospadias was screened for mutations in FGFR2, FGF10, FGF8, and BMP7 genes, using DHPLC and DNA sequence analysis. The sequence variations $c .590 \mathrm{C}>\mathrm{G}$ and $\mathrm{c} .582-62 \mathrm{G}>\mathrm{A}$ in $F G F 8$, and, c.550 + 27C $>$ T, c.727 + 180T $>$ G, c.830T $>C$ (p.Me186Thr), and c.2454C $>$ T in FGFR2 were found uniquely in patients with hypospadias, as compared with 96 controls. No genetic variant in the other genes was detected. These results indicate that mutations are rare in FGF8 and FGFR2 in hypospadias, but gene variants may influence the risk.

European Journal of Human Genetics (2007) 15, 405-410. doi:10.1038/sj.ejhg.5201777; published online 31 January 2007

Keywords: hypospadias; genitourinary development; FGFR2; FGF10; FGF8; BMP7

\section{Introduction}

Hypospadias is a common inborn error of the male genital development, affecting $0.3-7$ of 1000 live male births

\footnotetext{
*Correspondence: Dr A Beleza-Meireles, Department of Molecular Medicine and Surgery, CMM 02, Karolinska University Hospital, Karolinska Institutet, SE-171 76 Stockholm, Sweden.

Tel: + 4685177 6408; Fax: + 4685177 3620;

E-mail: ana.beleza@ki.se or agneta.nordenskjold@ki.se

${ }^{4}$ These authors contributed equally to this work.

Received 19 July 2006; revised 7 November 2006; accepted 6 December 2006; published online 31 January 2007
}

worldwide, resulting from failure of urethral tube closure at the genital tubercle (GT) in the gestational weeks $8-16 .^{1}$ Despite being common, the etiology of hypospadias is largely unknown. Both genetic and environmental factors have been suggested. ${ }^{2,3}$ Studies on the molecular mechanisms underlying normal penile development have revealed some possible developmental disturbances that may lead to hypospadias.

The urethral development starts with the formation of the urogenital sinus in the sixth week of gestation, followed by outgrowth of the genital tubercle with 
proximo-distal and dorso-ventral patterning, and epithelial tubulogenesis. By the eighth gestational week, a coordinated network of morphogenetic events, controlled by a network of signaling molecules, starts taking place even before the sexually dimorphic hormonally controlled phase. ${ }^{4}$ These processes are orchestrated by the urethral plate epithelium (UPE), at the GT, which has a polarizing activity. ${ }^{5,6}$ Sonic hedgehog (Shh), expressed at the UPE, is required for outgrowth and patterning of the genital tubercle and mice with a targeted deletion of shh have penile and clitoral agenesis. ${ }^{7}$ Shh regulates the expression of fibroblast growth factor $8(F g f 8)$ and mesenchymally expressed genes, including Hoxd13. The Hoxa13 and Hoxd13 genes play an essential role in external genital development. Mutations in the human HOXA13 gene is responsible for the range of phenotypes seen in handfoot-genital syndrome (HFGS), which includes hypospadias as a manifestation. ${ }^{8}$ Mice mutant for Hoxa13 are a phenocopy of HFGS, presenting a mild form of hypospadias. ${ }^{9}$ However mutations in $\mathrm{HOXA13}$ are not found in isolated hypospadias. ${ }^{10}$

Fgf8, or androgen (AR)-induced growth factor, is expressed during the initial GT outgrowth and marks the distal part of the UPE, thereby upregulating the expression of Fgf10, Bmp4 and Hoxd13. ${ }^{11}$ Bone morphogenic proteins (BMPs) and their antagonists are spatiotemporally expressed during GT development. In mice, exogenously applied BMP increases apoptosis of GT and inhibits its outgrowth. ${ }^{12}$ Moreover, hypospadias in the Hoxa13-/mice occurs as a result of the combined loss of Fgf8 and Bmp7 expression in the UPE. ${ }^{9}$ FGF10 is an important morphogen of the most distal GT structures, the glans penis and the glans clitoridis. Fgf10-/- deficient mutant male mice, as well as mice lacking the IIIb isoform of Fgfr2, exhibit a phenotype consistent with hypospadias, with normal corporal bodies, but disturbed urethral plate ventral fusion. ${ }^{13,14}$ In these mice, urethral signaling regions are established, but cell proliferation is prematurely arrested and maturation of the urethral epithelium is disrupted. Interestingly, these genes are downstream targets of AR during external genital development, as the loss of Fgfr2-IIIb and Fgf10 expression in the urethra, and associated hypospadias phenotype, is observed as an effect of AR antagonists. ${ }^{14}$

These observations prompted us to screen the FGFR2, FGF10, FGF8, and BMP7 and genes in boys with hypospadias.

\section{Patients and methods Patients and controls}

Sixty boys with non-syndromic hypospadias were selected through medical records in Sweden, all with at least one affected relative. Forty-seven were of Swedish origin, 12 of Middle-Eastern origin and one came from Finland. Thirty boys presented mild, 13 moderate and three severe hypospadias. In the remaining 14 boys, the severity of hypospadias is not available. As control group, we used DNA from an anonymous sample constituted by 96 healthy voluntary blood donors at Karolinska University Hospital, Stockholm. DNA was extracted from EDTApreserved blood, and isolated according to standard procedures.

\section{PCR and mutation screening}

Genomic sequences were obtained at the National Center for Biotechnology Information (NCBI) and confirmed at Ensembl Genome Browser. Primers were designed using Primer 3 program, with standard selection criteria, with average fragments size between 200 and $600 \mathrm{bp}$. PCR reactions were performed with AmpliTaq Gold ${ }^{\circledR}$ (Applied Biosystems) and Platinum ${ }^{\circledR}$ Taq (Invitrogen) using standard protocols. Sequences were analyzed by denaturing high-performance liquid chromatography (DHPLC) and direct sequencing analysis, according to the manufacturer's protocol. ${ }^{15,16}$ DHPLC was carried out on an automated WAVE instrument equipped with a DNASep column (Transgenomic Inc., Omaha, NE, USA). Column temperature was selected for optimal heteroduplex separation, using WAVERMAKER 3.4 software. For all samples exhibiting abnormal DHPLC profiles, and for FGFR2, as homozygous SNPs were expected, genomic DNA was evaluated by direct sequencing using BigDye ${ }^{\circledR}$ Terminator v1.3 sequencing kit (Applied Biosystems) and analyzed in ABI Prism 3730 Sequencer (PE Applied Biosystems, Foster City, CA, USA). Postsequencing analysis was performed with SeqScape v2.5 (Applied Biosystems). Statistica 7.0 was used for statistical analysis. Gene symbols follow standard recommendation. ${ }^{17,18}$

\section{Homology and structure predictions}

Splicing prediction was performed with Splice Site Prediction by Neural Network, Barkley Drosophila Genome Project. Putative homologs of human FGFR2 were detected by HomoloGene. The alignments were made with ClustalW software. Secondary structures were predicted with NNPREDICT, University of California. 3D Structure predicted at Protein Homology/analogY Recognition Engine from the Structural Bioinformatics Group, Imperial College, London.

\section{Results}

In FGF8, in the segment constituted by the exon 6 and adjacent intronic sequences, four Swedish patients of presented two heterozygous sequence variants (Table 1, Figure 1). Three of those presented the variant rs3218238 or c.582-62G $>A$ (or IVS6-62G $>A$ ). This SNP was not detected in a control population of 96 individuals, thus resulting in a statistically significant difference (analysis 
Table 1 All genetic variants that were found in the screening

\begin{tabular}{|c|c|c|c|c|c|c|c|}
\hline Gene & Gene variant & $R S N r$ & Alleles & Patients & Controls & P-value & $\begin{array}{l}\text { Minor allele } \\
\text { frequency }\end{array}$ \\
\hline $\begin{array}{l}\text { FGF8 } \\
\text { FGF8 } \\
\text { FGFR2 } \\
\text { FGFR2 } \\
\text { FGFR2 } \\
\text { FGFR2 } \\
\text { FGFR2 }\end{array}$ & $\begin{array}{l}\text { c. } 590 \mathrm{C}>\mathrm{G} \\
\text { c. } 5 \mathrm{~S} 2-62 \mathrm{G}>\mathrm{A} \\
\text { c. } 382+52 \rightarrow \mathrm{G} \\
\text { c. } 550+27 \mathrm{~T}>\mathrm{C} \\
\text { c. } 727+180 \mathrm{~T}>\mathrm{G} \\
\text { c. } 330 \mathrm{~T}>\mathrm{C} \\
\text { c. } 2454 \mathrm{C}>\mathrm{T}\end{array}$ & $\begin{array}{l}\mathrm{a} \\
\mathrm{rs} 3218233 \\
\mathrm{a} \\
\mathrm{a} \\
\mathrm{a} \\
\mathrm{rs} 755793 \\
\mathrm{a}\end{array}$ & $\begin{array}{l}\mathrm{C} / \mathrm{C} \\
\mathrm{G} / \mathrm{A} \\
-/ \mathrm{G} \\
\mathrm{T} / \mathrm{C} \\
\mathrm{T} / \mathrm{C} \\
\mathrm{T} / \mathrm{C} \\
\mathrm{C} / \mathrm{T}\end{array}$ & $\begin{array}{l}1 \\
3 \\
1 \\
1 \\
3 \\
1 \\
1\end{array}$ & $\begin{array}{l}0 \\
0 \\
0 \\
0 \\
0 \\
0 \\
0\end{array}$ & $\begin{array}{l}\mathrm{b} \\
0.05^{\mathrm{c}} \\
0.05^{\mathrm{c}} \\
0.05^{\mathrm{c}} \\
0.05^{\mathrm{c}} \\
\mathrm{b} \\
\mathrm{b}\end{array}$ & $\begin{array}{l}\mathrm{b} \\
0.045^{\mathrm{d}} \\
\mathrm{b} \\
\mathrm{b} \\
\mathrm{a} \\
0^{\mathrm{e}} \\
\mathrm{b}\end{array}$ \\
\hline FGFR2 & c. $959 G>A$ & rs1047100 & $\begin{array}{l}\mathrm{G} / \mathrm{G} \\
\mathrm{G} / \mathrm{A} \\
\mathrm{A} / \mathrm{A}\end{array}$ & $\begin{array}{r}28 \\
15 \\
3\end{array}$ & $\begin{array}{r}33 \\
26 \\
3\end{array}$ & $>0.05^{f}$ & $0.250^{\mathrm{e}}$ \\
\hline $\begin{array}{l}\text { FGFR2 } \\
\text { FGFR2 } \\
\text { FGFR2 } \\
\text { FGFR2 } \\
\text { FGFR2 } \\
\text { FGFR2 }\end{array}$ & $\begin{array}{l}\text { c. } 2136-43 \rightarrow G \\
\text { c. } 423 G>A \\
\text { c. } 213 G-17 G>T \\
\text { c. } 2331-95 G>A \\
\text { c. } 2331-31 A>G \\
\text { c. } 2575+18 G>A\end{array}$ & $\begin{array}{l}\text { rs4S4751; } \\
\text { rs1047101 } \\
\text { rs3135802 } \\
\text { rs1613776 } \\
\text { rs3135805 } \\
\text { a }\end{array}$ & $\begin{array}{l}-/ \mathrm{G} \\
\mathrm{G} / \mathrm{A} \\
\mathrm{G} / \mathrm{T} \\
\mathrm{G} / \mathrm{A} \\
\mathrm{A} / \mathrm{G} \\
\prod_{\mathrm{T}} \\
\mathrm{T} / \mathrm{C} \\
\mathrm{C} / \mathrm{C}\end{array}$ & $\begin{array}{r}11 \\
1 \\
2 \\
5 \\
2 \\
16 \\
22 \\
8\end{array}$ & $\begin{array}{r}23 \\
1 \\
2 \\
8 \\
6 \\
34 \\
46 \\
14\end{array}$ & $\begin{array}{l}>0.05^{f} \\
>0.05^{c} \\
>0.05^{c} \\
>0.05^{c} \\
>0.05^{c} \\
>0.05^{f}\end{array}$ & $\begin{array}{l}0^{\mathrm{e}} \\
0^{\mathrm{g}} \\
0.008^{\mathrm{g}} \\
0.033^{\mathrm{e}} \\
0.042^{\mathrm{e}} \\
\mathrm{b}\end{array}$ \\
\hline
\end{tabular}

${ }^{a}$ No RS number known.

${ }^{\mathrm{b}}$ Not applicable.

'Fisher's exact test.

dPDR90.

${ }^{\mathrm{f}} \chi^{2}$ test.

AFD_EUR_PANEL.

gHapMap-CEU.

FGF8

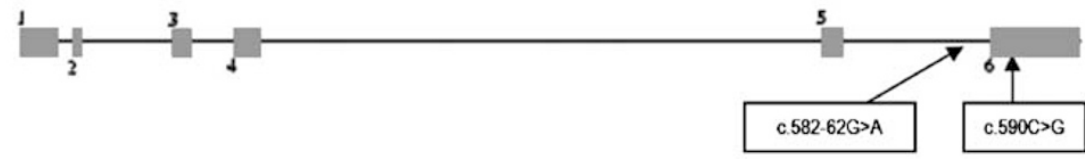

FGFR2

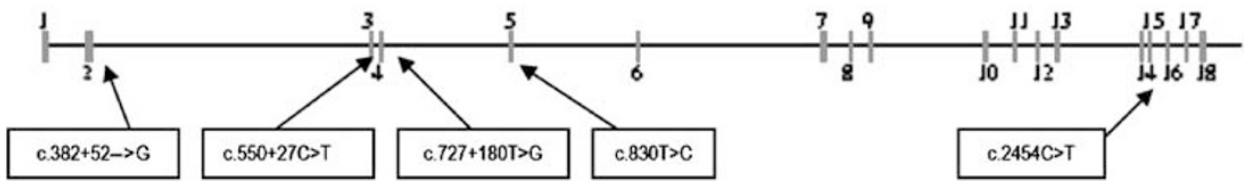

Figure 1 Gene variants in FGF8 and FGFR2 detected in our hypospadias patients.

with Fisher's test; $P<0,05)$. Another patient of Swedish origin presented a synonymous c.590C $>\mathrm{G}$ sequence variation. The 96 controls did not present this SNP. This gene variation has not been previously described, and may represent a private mutation.

Several single-nucleotide variations were found in heterozygous form in FGFR2 (Table 1, Figure 1): The variants c.830T $>$ C/p.Met186Thr $\quad$ (rs755793), c.382 $+52 \rightarrow \mathrm{G}$ $(\mathrm{IVS} 2+52 \rightarrow \mathrm{G}), \mathrm{c} .550+27 \mathrm{C}>\mathrm{T}(\mathrm{IVS} 3+27 \mathrm{C}>\mathrm{T})$ and the synonymous c.2454C $>\mathrm{T}$ are found in patients of Swedish origin and are not present in the control population. The variation c.727 $+180 \mathrm{~T}>\mathrm{G}$ (IVS4 $+180 \mathrm{~T}>\mathrm{G})$ is present in three non-related Swedish patients (analysis with Fisher's test; $P<0,05)$. None of the above-mentioned variations were found in the control population. The variants c. $382+52 \rightarrow \mathrm{G} \quad(\mathrm{IVS} 2+52 \rightarrow \mathrm{G}), \quad$ c. $550+27 \mathrm{C}>\mathrm{T} \quad$ (IVS $3+$ $27 \mathrm{C}>\mathrm{T}), \quad$ c. $2454 \mathrm{C}>\mathrm{T}$ and $\quad$ c. $727+180 \mathrm{~T}>\mathrm{G} \quad(\mathrm{IVS} 4+180$ $\mathrm{T}>\mathrm{G})$ may represent private mutations. None of these sequence variants is predicted to cause any splicing alteration or protein structure modifications by the previously mentioned methods. Other gene variants were found in this gene: rs1047100, rs4647915, rs1047101, 


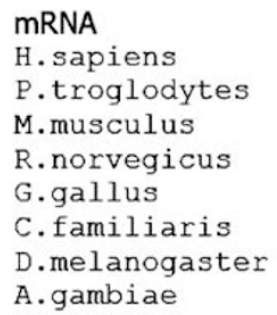

\section{Protein}

\section{H. sapiens}

P.troglodytes

M.musculus

R. norvegicus

G.gallus

C.familiaris

D.melanogaster

A. gambiae

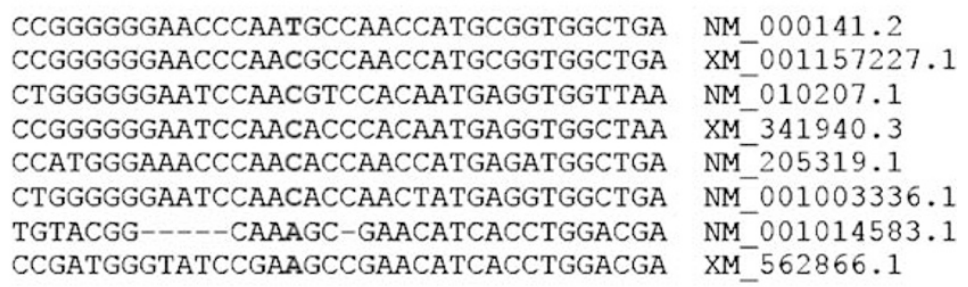

\author{
NM_000141.2 \\ XM 001157227.1 \\ NM-010207.1 \\ XM_341940.3 \\ NM 205319.1 \\ NM_001003336.1 \\ NM 001014583.1 \\ $\mathrm{XM}^{-} 562866.1$
}

AANTVKFRCPAGGNPMPTMRWLKNGKEEKQEHRIGG AANTVKFRCPAGGNPTPTMRWLKNGKEFKQEHRIGG AANTVKFRCPAGGNPTSTMRWLKNGKEFKQEHRIGG AANTVKFRCPAGGNPTPTMRWLKNGKEFKQEHRIGG AANTVKFRCPAMGNPTPTMRWLKNGKEFKQEHRIGG AANTVKFRCPAGGNPTPTMRWLKNGKEFKQEHRIGG SGNTVNLACPVYG--KANITWTKDKK--PLNRELGSGNMVRLRCPADGYPKPNITWTKDGR--KIERAMG-

Figure 2 Putative homolog of human FGFR2, according to HomoloGene, a system for automated detection of homologs among the annotated genes of several completely sequenced eukaryotic genomes. The ClustalW software produced mRNA and protein alignments. The Met in the p.Met186Thr variant (rs755793) is not conserved.

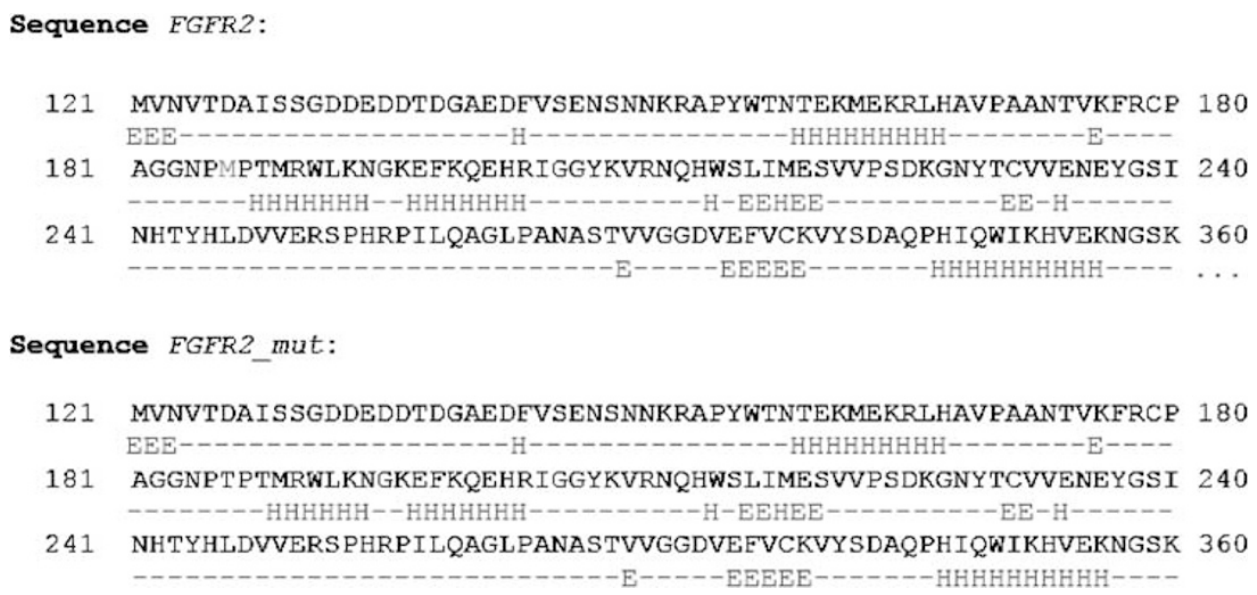

Figure 3 Secondary structure prediction with NNPREDICT ( $\mathrm{H}=$ helix, $\mathrm{E}=$ strand, - = no prediction) http://www.cmpharm.ucsf.edu/ nomi/ nnpredict.html. No secondary structure alteration is caused by the rs 755793 variant.

rs3135802, rs1613776, rs3135806 and c. $2575+15 \mathrm{C}>\mathrm{T}$ $($ IVS17 $+15 \mathrm{C}>\mathrm{T})$, but all are in the same frequency as the control population.

The SNP c.830T > C is the only non-synonymous variant found; converting the amino acid 186 from a hydrophobic (methionine) to hydrophilic (threonine) amino acid. The affected patient is Swedish, and presented a mid-penile type of hypospadias, which is a moderate phenotype. He also presents one of the other variants in the same gene $($ c. $382+52 \rightarrow \mathrm{G})$. This SNP rs755793 has not been reported in the Caucasian population, but in the Asian and in the Sub-Saharan African, where the $\mathrm{C}$ allele has a frequency of 0.067 and 0.392, respectively, according to HapMap data. This SNP is located in the Ig-like C2-type 1 extracellular domain of the protein (UniProtKB/Swiss-Prot entry P21802), therefore crucial to the ligand binding. However, neither homology nor protein structure predictions suggest any functional implications of this gene variant (Figures 2-4).

No sequence variants were found in BMP7 or in FGF10.

\section{Discussion}

The mechanisms underlying the genital development are not fully understood. FGFs and BMPs and their receptors belong to a rather compact group of 'tool kit' genes, which participate in several developmental pathways, and used redundantly to build the different organs, including the genitourinary structures. ${ }^{19}$ Furthermore, these genes have a role in murine hypospadias. Although extrapolation to 

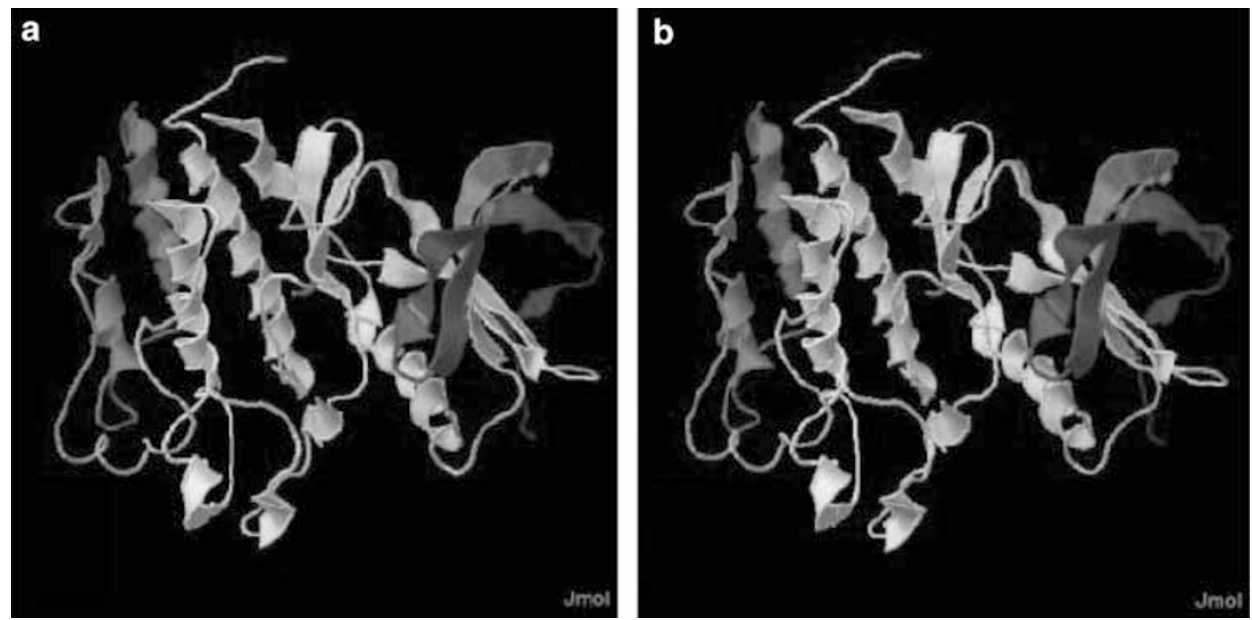

Figure 4 3D Structure prediction: (a), FGFR2, the normal variant (estimated precision: 100\%) and (b), FGFR2mut, with the variant p.Met186Thr (estimated precision: 100\%). Although the SNP rs755793 (p.Met186Thr) is non-synonymous, converting the amino acid 186 from methionine (hydrophobic) to threonine (hydrophilic), it does not seem to change the protein structure. Predicted at Protein Homology/analogY Recognition Engine/Structural Bioinformatics Group, Imperial College, London.

human development should be carried out critically, the high conservativeness of these pathways suggests that the same molecules might also be involved in hypospadias in humans.

In our study, gene variants in both $F G F 8$ and $F G F R 2$ were implicated in hypospadias. The two sequence variants on FGF8 that were found are located around a region coding to the $\mathrm{COOH}$-terminal portion of the protein. This carboxyl region is shared by all the reported products of alternative splicing of this gene, which therefore might be of importance to the protein function. However, none of these gene variants alter the predicted protein structure. The sequence variants found in FGFR2 are more diverse, and their functional consequences more difficult to predict. The only non-synonymous variant (p.Met186Thr), as well as all the others, did not reveal any functional consequence according to homology and to protein structure prediction. But larger studies would be needed to elucidate the role of this variation. Also the combination of this SNP in a patient with another variant in the same gene may suggest a risk haplotype, or a cumulative effect of different gene variants. It is possible that the sequence variants that were found might cause different structural folds of mRNA, or altered splicing, or be in linkage disequilibrium with functional regulatory mutations or polymorphisms.

FGF8 is induced by AR through an AR receptor mediated expression mechanism. This regulation acts through its androgen response element (ARE) sequences in $F G F 8^{\prime}$ s promoter. ${ }^{20-22}$ Fgfr2-IIIb has been shown to mediate the closure of the urethral tube through an AR-dependent process. The antagonism of AR leads to the downregulation of Fgfr2-IIIb in mouse genitalia. The presence of an AR binding site in the Fgfr2 promoter also supports an interaction between the two receptors. ${ }^{13-14}$

The study has been performed by standard methods to detect mutations and other gene variants, with a sensitivity of near, but not exactly $100 \%$. Therefore, some gene variants might still have been missed. Nevertheless, our study populations consisted of familiar cases, in order to increase the chance of finding genetic causes of hypospadias. The fact that we did not find coding mutations in such group, therefore, strengthens the conclusion that mutations in these genes are not important in the pathogenesis of human hypospadias. Additionally, the absence of gene variations in BMP7 and FGF10 in this study does not necessarily mean that these genes are not involved in hypospadias; however, it does not encourage further studies.

The present work is based on selected candidate genes, implicating gene variants, but not mutations, of $F G F 8$ and FGFR2 in hypospadias. As male genital development is an AR-dependent process, one could speculate that the polymorphisms found in the FGF8 and FGFR2 genes of boys with hypospadias might interfere with AR responses during urethral development.

\section{Acknowledgements}

We acknowledge Ingrid Kockum and Tatjana Djureinovic for their support, as well as the Portuguese Fundação para a Ciência $e$ Tecnologia, which finances A B-M. This work was also supported by grants from HRH Crown Princess Lovisa Foundation, the Swedish Research Council, Frimurarna, Åke Wiberg Foundation, Magnus Bergvall Foundation, Marcus Borgström Foundation, Karolinska Institute, Erik Rönnberg donationer (Riksbankens jubileumsfond) and the Swedish Society of Medicine. 


\section{References}

1 Paulozzi L: International trends in rates of hypospadias and cryptorchidism. Environ Health Perspect 1999; 107: 297-302.

2 Fredell L, Iselius L, Collins A et al: Complex segregation analysis of hypospadias. Hum Genet 2002; 111: 231-234.

3 Manson JM, Carr MC: Molecular epidemiology of hypospadias: review of genetic and environmental risk factors. Birth Defects Res A Clin Mol Teratol 2003; 67: 825-836.

$4 \mathrm{Kim}$ KS, Liu W, Cunha GR et al: Expression of the androgen receptor and 5 alpha-reductase type 2 in the developing human fetal penis and urethra. Cell Tissue Res 2002; 307: $145-153$.

5 Baskin LS, Erol A, Jagatheesan P, Li Y, Liu W, Cunha GR: Urethral seam formation and hypospadias. Cell Tissue Res 2001; 305: 379-387.

6 Yamada G, Satoh Y, Baskin LS, Cunha GR: Cellular and molecular mechanisms of development of the external genitalia. Differentiation 2003; 71: 445-460.

7 Morgan EA, Nguyen SB, Scott V, Standler S: Loss of Bmp7 and Fgf8 signaling in HOXA13-mutant mice causes hypospadia. Development 2003; 130: $3095-3109$.

8 Perriton CL, Powles N, Chiang C, Maconochie MK, Cohn MJ: Sonic hedgehog signaling from the urethral plate epithelium controls external genitalia development. Dev Biol 2002; 247: $26-46$.

9 Goodman FR, Scambler PJ: Human HOX gene mutations. Clin Genet 2001; 59: 1-11.

10 Utsch B, Kaya A, Özburun A, Lentze MJ, Alberts N, Ludwig M: Exclusion of WTAP and HOXA13 as candidate gene for isolated hypospadias. Scand J Urol Nephrol 2003; 37: 498-501.

11 Haraguchi R, Suzuki K, Murakami R et al: Molecular analysis of external genitalia formation: the role of fibroblast growth factor (Fgf) genes during genital tubercle formation. Development 2000; 127: $2471-2479$.

12 Suzuki K, Bachiller D, Chen YP et al: Regulation of outgrowth and apoptosis for the terminal appendage: external genitalia: development by concerted actions of BMP signaling. Development 2003; 130: 6209-6220.

13 Yucel S, Liu W, Cordero D, Donjacour A, Cunha G, Baskin LS Anatomical studies of the fibroblast growth factor-10 mutant, sonic hedge hog mutant and androgen receptor mutant mouse genital tubercle. Adv Exp Med Biol 2004; 545: 123-148.

14 Petiot A, Perriton CL, Dickson C, Cohn MJ: Development of the mammalian urethra is controlled by Fgfr2-IIIb. Development 2005; 132: $2441-2450$.

15 Gross E, Arnold N, Goette J, Schwarz-Boeger U, Kiechle M: A comparison of BRCA1 mutation analysis by direct sequencing, SSCP and DHPLC. Hum Genet 1999; 105: 72-78.

16 Bunn CF, Lintott CJ, Scott RS, George PM: Comparison of SSCP and DHPLC for the detection of $L D L R$ mutations in a New Zealand cohort. Hum Mutat 2002; 19: 311.

17 Povey S, Lovering R, Bruford E, Wright M, Lush M, Wain H: The HUGO Gene Nomenclature Committee (HGNC). Hum Genet 2001; 109: 678-680.

18 den Dunnen JT, Antonarakis SE: Mutation nomenclature extensions and suggestions to describe complex mutations: a discussion. Hum Mutat 2000; 15: 7-12.

19 Scott FG: Developmental Biology; 7th edn Sinauer Associates Inc, 2003.

20 Payson RA, Wu J, Liu Y, Chiu IM: The human FGF-8 gene localizes on chromosome 10q24 and is subjected to induction by androgen in breast cancer cells. Oncogene 1996; 13: 47-53.

21 Lorenzi MV, Long JE, Miki T, Aaronson SA: Expression cloning, developmental expression and chromosomal localization of fibroblast growth factor-8. Oncogene 1995; 10: 2051-2055.

22 Gnanapragasam VJ, Robson CN, Neal DE, Leung HY: Regulation of $F G F 8$ expression by the androgen receptor in human prostate cancer. Oncogene 2002; 21: 5069-5080. 